\title{
Bioequivalence of a Newly Developed Dabigatran Etexilate Tablet Versus the Commercial Capsule and Impact of Rabeprazole-Induced Elevated Gastric pH on Exposure in Healthy Subjects
}

\author{
Akiko Harada $^{1}$ @ $\cdot$ Ippei Ikushima ${ }^{2} \cdot$ Miwa Haranaka $^{3} \cdot$ Aki Yanagihara $^{4} \cdot$ Daisuke Nakayama $^{4}$
}

Published online: 30 October 2019

(c) The Author(s) 2019

\begin{abstract}
Background and Objective Dabigatran etexilate (DE) is an anticoagulant with proven efficacy and tolerability for stroke prevention in patients with non-valvular atrial fibrillation. For the commercial capsule, a complex formulation is used to maintain the acidic microenvironment required for maximal absorption. Consequently, its efficacy and safety are similar with or without concomitant intake of proton-pump inhibitors (PPIs). A simplified DE tablet formulation was developed and tested in two studies. One investigated bioequivalence (BE) of the novel DE tablet versus the commercial DE capsule. The other investigated DE bioavailability (BA) under pretreatment with the PPI rabeprazole and assessed the effect of elevated $\mathrm{pH}$ on exposure to dabigatran.

Methods BE of the novel DE tablet versus the DE capsule was assessed in a randomized two-treatment, four-period, twosequence crossover study (NCT03070171). The effect of rabeprazole on the BA of the DE tablet was assessed in an openlabel, single-arm study (NCT03143166). Both studies were conducted at sites in Japan. Participants were healthy male volunteers, aged $\geq 20-40$ years. In the BE study, participants received the DE tablet or capsule (single oral dose, $110 \mathrm{mg}$ ); primary endpoints were area under the concentration-time curve from baseline to the last quantifiable data point (AUC $\left.{ }_{0-\mathrm{tz}}\right)$ and maximum plasma concentration $\left(C_{\mathrm{max}}\right)$ of unconjugated dabigatran. In the relative BA study, participants received the $\mathrm{DE}$ tablet (single oral dose, $110 \mathrm{mg}$ ) with or without rabeprazole pretreatment (once daily for 5 days, $20 \mathrm{mg}$ ); primary endpoints were $\mathrm{AUC}_{0-\mathrm{tz}}$ and $C_{\max }$ of total dabigatran.

Results In total, 160 participants were randomized in the BE study; 36 participants were enrolled in the BA study. The $90 \%$ confidence intervals of geometric mean (gMean) ratios for $\mathrm{AUC}_{0-\mathrm{tz}}(101.4-116.0 \%)$ and $C_{\max }(101.8-116.6 \%)$ of unconjugated dabigatran were within pre-defined acceptance criteria for $\mathrm{BE}$. In the relative $\mathrm{BA}$ study, the gMeans of $\mathrm{AUC}_{0-\mathrm{tz}}(667$ to $192 \mathrm{ng} \mathrm{h} / \mathrm{mL}$ ) and $C_{\max }(83.1$ to $21.8 \mathrm{ng} / \mathrm{mL}$ ) were decreased by approximately $70 \%$ when the tablet was administered under rabeprazole pretreatment. The reduction in $\mathrm{BA}$ was observed at a mean gastric $\mathrm{pH}$ of 5.3. Treatment was well tolerated; no deaths, serious adverse events (AEs) or significant AEs were reported in either study.

Conclusion The DE tablet demonstrated BE to the capsule; however, at high gastric pH, BA of the tablet was reduced by approximately $70 \%$, which may lead to reduced efficacy. Data indicate the importance of examining not only BE under standard conditions, but relative BA at elevated gastric $\mathrm{pH}$. Such investigations may avoid the reduced BA at elevated $\mathrm{pH}$ that is quite common in the target population (the elderly and/or patients treated with gastric-acid modifying co-medications), and therefore reduce treatment failure with DE.
\end{abstract}

Registration: ClinicalTrials.gov identifier numbers: NCT03070171, and NCT03143166

\section{Introduction}

Dabigatran etexilate (DE) is an oral prodrug that is rapidly converted to dabigatran, an anticoagulant that exerts its

Akiko Harada

akiko.harada@boehringer-ingelheim.com

Extended author information available on the last page of the article effect through direct inhibition of thrombin. DE has efficacy and safety outcomes similar or superior to warfarin for stroke prevention in patients with non-valvular atrial fibrillation (NVAF) [1]. In the RE-LY study, dabigatran $150 \mathrm{mg}$ twice daily (BID) was superior to warfarin with respect to prevention of stroke or systemic embolism (the primary efficacy outcomes), but was associated with similar rates of major bleeding. The 110-mg BID dosage demonstrated 


\section{Key Points}

Dabigatran etexilate (DE), converted to active dabigatran in the body, is administered orally. Its availability in the body is dependent on the acidity of the stomach.

The current study shows that in healthy young subjects, with a consistently acidic environment in the stomach, there are no significant differences in the blood levels of dabigatran after taking the new DE tablet versus the existing drug capsule.

However, the amount of dabigatran found in the circulation was reduced by about $70 \%$ when the tablet was given to healthy young individuals pretreated with a stomach-acid-reducing drug. This diminished availability in the blood may result in a high risk of drug failure in elderly patients, who often experience an elevated gastric $\mathrm{pH}$. Hence, when developing a new formulation of a drug with $\mathrm{pH}$-dependent solubility such as DE, investigating the effect of agents that neutralize stomach acid should be considered, even though current regulations do not consistently mandate these investigations in clinical trials.

non-inferiority to warfarin on the primary efficacy outcomes, but was superior for the outcome of major bleeding [1]. Moreover, subanalyses from the RE-LY study demonstrated the efficacy and safety of dabigatran $110 \mathrm{mg}$ BID and $150 \mathrm{mg}$ BID in Asian and Japanese patients [2, 3]. In addition, a Japanese post-marketing surveillance (PMS) study showed a favorable risk-benefit profile of DE in Japanese patients with NVAF [4]. In guidelines published by the Japanese Circulation Society, the American Heart Association, and the American College of Cardiology, DE is recommended as an alternative to warfarin for $\operatorname{NVAF}[5,6]$.

In Japan, DE is currently available as 75- or 110-mg capsule formulations [7]; however, there is a need to develop an alternative DE formulation that is smaller than the capsule, which may have advantages for elderly patients or patients after stroke, who have difficulty in swallowing [8, 9]. Atrial fibrillation (AF) is more commonly seen in the elderly, and its prevalence has increased both in Japan and in Western countries due to an aging population [10]. In the PMS study in Japan, $60 \%$ of patients who received DE were aged $\geq 70$ years [4].

The solubility of $\mathrm{DE}$ is $\mathrm{pH}$ sensitive and decreases at more neutral $\mathrm{pH}$ ranges. The current capsule formulation is designed to maintain bioavailability (BA) in conditions of elevated gastric $\mathrm{pH}$ or fasting [11]. Co-administration of DE with proton-pump inhibitors (PPIs) could decrease its solubility, potentially leading to reduced BA. To counteract any $\mathrm{pH}$ dependence of solubility, commercially available DE capsules contain pellets comprising a tartaric acid core with a DE coating; the acid maintains the low-pH environment necessary for DE solubilization and optimizes BA [12]. Clinical evidence from the RE-LY study supports consistent efficacy and safety of the DE capsule with or without concomitant PPI [1, 13], and dose adjustment is not required in the current labeling [7]. However, given that most patients with NVAF are elderly, and concomitant use of PPIs is likely, it is important that the efficacy and safety of novel $\mathrm{DE}$ formulations are tested at elevated gastric $\mathrm{pH}$ levels.

Several candidate DE tablets were developed, and one of five tablet formulations was selected for further evaluation, via a BA study (NCT02710630). Here, we report the data from two subsequent studies assessing this novel DE oral formulation: one study assessed bioequivalence (BE) versus the commercially available capsule formulation as per regulatory requirements, and conducted according to current $\mathrm{BE}$ guidelines [14]; and the other study assessed BA under pretreatment with the PPI rabeprazole, to investigate the influence of elevated gastric $\mathrm{pH}$ on exposure to the novel DE tablet.

\section{Methods}

\subsection{Study Designs}

\subsubsection{Bioequivalence of the DE Tablet Versus Capsule}

This was a randomized two-treatment, four-period, twosequence crossover study to assess the $\mathrm{BE}$ of the $\mathrm{DE}$ $110-\mathrm{mg}$ tablet versus the commercially available $110-\mathrm{mg}$ capsule (NCT03070171). The study was conducted at the SOUSEIKAI Sumida Hospital, Tokyo, Japan.

Participants were randomized 1:1 to one of two sequences over four periods (test drug [T] and reference [R] periods: T-R-R-T and R-T-T-R; Fig. 1), using a validated, pseudorandom number generator. They received a single oral dose of one $110-\mathrm{mg}$ tablet or one 110-mg capsule on day 1 of each treatment period with $200 \mathrm{~mL}$ of water [14], following an overnight fast of minimum $10 \mathrm{~h}$. Treatments were separated by a washout period of at least 4 days.

\subsubsection{Bioavailability of the DE Tablet Alone and Under Rabeprazole Pretreatment}

This was an open-label, single-arm study to assess the BA of the 110-mg DE tablet alone (R) and under pretreatment with $20 \mathrm{mg}$ rabeprazole (T) (NCT03143166). The study was conducted at the SOUSEIKAI Hakata Clinic, Fukuoka, Japan.

All participants received the DE tablet on day 1, $20 \mathrm{mg}$ rabeprazole once daily from day 2 to day 6 inclusive, and 




Fig. 1 BE of the DE tablet versus capsule: randomization sequence and study design. There was a washout period of at least 4 days between treatment administrations. $B E$ bioequivalence, $D E$ dabi-

DE again on day $6,4 \mathrm{~h}$ after administration of rabeprazole (Fig. 2).

The DE tablet or capsule was administered as a single oral dose with $200 \mathrm{~mL}$ of water, following an overnight fast of minimum $10 \mathrm{~h}$. Compliance to treatment was guaranteed, as all trial medication was administered under the supervision of the investigator in the study center.

\subsection{Participants}

Healthy male participants from the volunteers' pool at the study site, aged $\geq 20$ and $\leq 40$ years at the time of informed consent, with a body mass index (BMI) of $\geq 18$ and $\leq 25 \mathrm{~kg} / \mathrm{m}^{2}$ at screening were included in the studies. Key exclusion criteria were as follows: measurements at screening outside the ranges for systolic blood pressure $(90-140 \mathrm{mmHg}$ ), diastolic blood pressure (50-90 $\mathrm{mmHg}$ ), or pulse rate (45-90 bpm); any clinically relevant medical history, concomitant disease, laboratory values outside the reference range, and drug use that may influence the study results; gastrointestinal surgery that could interfere with the kinetics of the study medication gatran etexilate, $R$ reference treatment: dabigatran etexilate commercial capsule formulation, $T$ test treatment: dabigatran etexilate tablet formulation, $N$ number of subjects

(except appendectomy and simple hernia repair); and smoking and alcohol abuse.

All procedures performed in the two studies involving human participants were in accordance with the ethical standards of the same institutional research committee (Hakata Clinic Institutional Review Board) and with the 1964 Helsinki declaration and its later amendments or comparable ethical standards. All participants provided written informed consent.

\subsection{Assessments and Endpoints}

Blood samples $(\sim 3 \mathrm{~mL})$ were collected into tubes containing tripotassium ethylenediaminetetraacetic acid (K3-EDTA) for pharmacokinetic analysis at baseline (within $3 \mathrm{~h}$ prior to treatment administration) and at 30,60, and 90 min and 2, 3, $4,6,8,12,24,36$, and $48 \mathrm{~h}$ after administration. Plasma was separated within $30 \mathrm{~min}$ of blood sampling by centrifugation at $4-8{ }^{\circ} \mathrm{C}$ and $2500 \mathrm{~g}$ for $10 \mathrm{~min}$. Plasma concentrations of unconjugated dabigatran and total dabigatran (plasma dabigatran plus dabigatran glucuronides, measured after alkaline



Fig. 2 BA of the DE tablet alone and under rabeprazole pretreatment: study design. BA bioavailability, DE dabigatran etexilate, EOT end of trial, $N$ number of subjects. ${ }^{1} \mathrm{DE}$ tablet was given $4 \mathrm{~h}$ after rabeprazole administration 
cleavage of glucuronic acid conjugates) were determined by a validated high-performance liquid chromatography tandem mass spectrometry (HPLCMS/MS) method at Nuvisan GmbH, Neu-Ulm, Germany. Calibration curves for unconjugated and total dabigatran covered a range from $1-400 \mathrm{ng} / \mathrm{mL}$ in undiluted plasma samples.

Intragastric $\mathrm{pH}$ was measured using a portable $\mathrm{pH}$ monitor. Data were collected at predose and within $2 \mathrm{~h}$ post-DE treatment.

Safety and tolerability were assessed throughout the study by frequency of adverse events (AEs), blood laboratory tests, 12-lead electrocardiogram (ECG), and vital signs (blood pressure, pulse rate).

\subsubsection{Bioanalytics}

For the determination of unconjugated dabigatran, $50 \mu \mathrm{L}$ of plasma were aliquoted, diluted with $50 \mu \mathrm{L} 0.2 \mathrm{M}$ ammonium formate buffer ( $\mathrm{pH} 3.5$ ), spiked with $40 \mu \mathrm{L}$ internal standard spiking solution $\left(100 \mathrm{ng} / \mathrm{mL}\left[{ }^{13} \mathrm{C}_{6}\right]\right.$ dabigatran) and mixed well. Afterwards the samples were centrifuged at $4{ }^{\circ} \mathrm{C}$ for 5 min.

For the determination of total dabigatran, $50 \mu \mathrm{L}$ of plasma were aliquoted, spiked with $40 \mu \mathrm{L}$ internal standard spiking solution $\left(100 \mathrm{ng} / \mathrm{mL}\left[{ }^{13} \mathrm{C}_{6}\right]\right.$ dabigatran) and mixed with $20 \mu \mathrm{L} 0.2 \mathrm{M} \mathrm{NaOH}$. After $2 \mathrm{~h}$ of incubation at $37{ }^{\circ} \mathrm{C}$ in order to cleave acyl glucuronides the samples were acidified with $30 \mu \mathrm{L} 0.2 \mathrm{M} \mathrm{HCl}$, mixed well and centrifuged at $4{ }^{\circ} \mathrm{C}$ for $5 \mathrm{~min}$.

For both analytes, approximately $90-100 \mu \mathrm{L}$ of the supernatants were transferred to autosampler vials. The method involved direct injection of $2.5 \mu \mathrm{L}$ onto an accumulation column $(60 \times 1 \mathrm{~mm}$ Reprosil G-RAMP) and subsequent transfer by column-switching onto the analytical $\mathrm{C}_{18}$ reversed phase HPLC column (YMC-Triart C18; $50 \times 2 \mathrm{~mm}, 3-\mu \mathrm{m}$ particle size) operated at $20{ }^{\circ} \mathrm{C}$ with gradient elution at a flow rate of $0.3 \mathrm{~mL} / \mathrm{min}$. Transitions from $\mathrm{m} / \mathrm{z}=472$ to $\mathrm{m} / \mathrm{z}=289$ and from $\mathrm{m} / z=478$ to $\mathrm{m} / z=295$ were recorded for dabigatran and $\left[{ }^{13} \mathrm{C}_{6}\right]$ dabigatran, respectively, while the transition from $m / z=648$ to $m / z=289$ was monitored for presence/absence of glucuronides.

Assay performance was well within acceptance limits, as shown by a mean quality control (QC) inaccuracy of within $\pm 2.8 \%$, mean QC imprecision of $\leq 8.6 \%$ and an incurred samples reanalysis (ISR) pass rate of $\geq 94.7 \%$ for both analytes across both studies.

\subsubsection{Bioequivalence of the DE Tablet Versus Capsule}

The purpose of this study was to demonstrate the BE of DE tablet compared with the commercial capsule formulation. The primary endpoints were the assessment of the area under the concentration-time curve from baseline to the last quantifiable data point $\left(\mathrm{AUC}_{0-\mathrm{tz}}\right)$ and the maximum plasma concentration $\left(C_{\max }\right)$ of unconjugated dabigatran for a $\mathrm{DE}$ tablet (T) and DE capsule (R). Unconjugated dabigatran was chosen as the primary endpoint for the BE study according to $\mathrm{BE}$ guidelines [14]. Secondary endpoints included assessments of $\mathrm{AUC}_{0-\mathrm{tz}}$ and $C_{\max }$ of total dabigatran and area under the concentration-time curve from baseline extrapolated to infinity $\left(\mathrm{AUC}_{0-\infty}\right)$ of unconjugated and total dabigatran.

\subsubsection{Bioavailability of the DE Tablet Alone and Under Pretreatment of Rabeprazole}

The purpose of this study was to evaluate the relative BA of the DE tablet alone and under pretreatment with $20 \mathrm{mg}$ rabeprazole. Dabigatran is the predominant metabolite, and further subject to conjugation with glucuronic acid [15]. Since the glucuronic acid conjugates of dabigatran have similar pharmacodynamic activity to the active moiety dabigatran itself, total dabigatran was considered the primary "biorelevant" pharmacokinetic readout and set as the primary endpoint analyte for this study. Therefore, the primary endpoint for BA was the evaluation of $\mathrm{AUC}_{0-\mathrm{tz}}$ and $C_{\max }$ of total dabigatran for the $\mathrm{DE}$ tablet alone $(\mathrm{R})$ and under pretreatment with rabeprazole $(T)$. Secondary endpoints included assessments of $\mathrm{AUC}_{0-\mathrm{tz}}$ and $C_{\max }$ of unconjugated dabigatran and $\mathrm{AUC}_{0-\infty}$ of unconjugated and total dabigatran.

Gastric $\mathrm{pH}$ was measured using a glass microelectrode inserted nasally on the days of DE tablet administration. Data were collected at baseline and 15, 30, 60, and $120 \mathrm{~min}$ after DE administration. A blood sample was used to check for CYP2C19 polymorphisms rs4244285, rs4986893, and rs12248560. Genotype results were used for allele classification $(* 1, * 2, * 3$, and $* 17)$ and subsequent categorization of participants as poor $(* 2 / * 2, * 2 / * 3$ and $* 3 / * 3)$, intermediate $(* 1 / * 2$ and $* 1 / * 3)$, extensive $(* 1 / * 1)$ and ultrarapid metabolizers $(* 1 / * 17$ or $* 17 / * 17)$.

\subsubsection{Statistical Analysis}

Pharmacokinetic parameters were analyzed by non-compartmental analysis using Phoenix Winnonlin version 6.3 (Pharsight ${ }^{\circledR}$ ). Ratios (test versus reference treatment) for pharmacokinetic endpoints were calculated in all participants who provided at least one pharmacokinetic measurement for both test and reference study treatments. Point estimates, geometric means (gMeans) and gMean ratios of natural log-transformed data, together with their two-sided $90 \%$ confidence intervals (CIs), were evaluated by analysis of variance (ANOVA).

For the BE study, if the $90 \%$ CIs of both ratios of the gMeans for the primary endpoints were within the predefined acceptance range (80-125\%), the two formulations would be considered BE. Therefore, no adjustment of the 
level of significance was necessary. The intra-individual geometric coefficient of variation (intra-individual $\mathrm{gCV}$ ) was also calculated.

\subsubsection{Safety Analyses}

Safety was assessed throughout the study in all participants who received at least one dose of study drug. AEs were documented using the Medical Dictionary for Regulatory Activities (MedDRA, version 20.0). The frequency, severity, and causal relationships of AEs were tabulated by treatment, system organ class, and preferred term. All AEs occurring between study drug administration (day 1) and the end of a period were considered to be treatment-emergent AEs. Serious AEs (SAEs) and other significant AEs were listed separately. Relevant ECG findings were also reported as AEs. Results of laboratory tests were compared with reference ranges and baseline data. Vital signs were compared with baseline data.

\section{Results}

\subsection{Bioequivalence of the DE Tablet Versus Capsule}

\subsubsection{Participant Demographics}

During the study (conducted from 22 March 2017 to 20 June 2017), 160 healthy male volunteers were randomized with 80 assigned to each treatment sequence (Fig. 1). All participants, except for two in the R-T-T-R group (one withdrew after period 1 for an unspecified reason and one withdrew consent during period 3), completed the study. Baseline demographics between the two groups were balanced: mean age (years \pm standard deviation $[\mathrm{SD}]$ ) was $27.2 \pm 4.2$ (range 20-36) and 27.3 \pm 4.2 (range 20-36) for the T-R-R-T and R-T-T-R period groups, respectively; BMI $\mathrm{kg} / \mathrm{m}^{2} \pm \mathrm{SD}$ was $21.1 \pm 1.9$ (range 18.0-25.0) and $21.5 \pm 1.8$ (range 18.0-25.0) for the T-R-R-T and R-T-T-R groups, respectively (Table 1).

\subsubsection{Pharmacokinetics}

The arithmetic mean plasma concentration-time profiles of unconjugated dabigatran were similar between the tablet and capsule formulations (Fig. 3). Plasma concentrations of unconjugated dabigatran (primary endpoint) were generally detectable for both tablet and capsule formulations until 36 or $48 \mathrm{~h}$ after administration. Unconjugated dabigatran reached peak plasma concentration $2 \mathrm{~h}$ after administration for both the tablet and capsule. $\mathrm{AUC}_{0-\mathrm{tz}}$ and $C_{\max }$ for unconjugated dabigatran were comparable between the two formulations (Table 2). Similar results were demonstrated for total dabigatran (Table 2).

The 90\% CIs of gMean ratios of $\mathrm{AUC}_{0-\mathrm{tz}}(101.4-116.0)$ and $C_{\max }(101.8-116.6)$ of unconjugated dabigatran were within the pre-defined acceptance range for BE $(80-125 \%$; Table 2). Intra-individual variation was comparable between the DE tablet and capsule formulations for both of these parameters, respectively $(57.0 \%$ and $56.4 \%$ for the tablet; $52.3 \%$ and $55.2 \%$ for the capsule; Table 2). The $90 \%$ CIs of adjusted gMean ratios of $\mathrm{AUC}_{0-\infty}$ (secondary endpoint) of unconjugated dabigatran were also within the acceptance range for $\mathrm{BE}$ (Table 2).

\subsubsection{Safety}

Single doses of DE tablet and capsule were generally well tolerated, and AEs were manageable. Of the 160 participants, two participants (1.3\%) (one for each formulation) experienced a non-severe treatment-emergent AE. Treatment-emergent AEs observed in both of these patients were nausea and vomiting. The patient treated with the tablet formulation also experienced headache, abdominal pain, and diarrhea, while the patient receiving the capsule formulation experienced the preferred term of feeling abnormal. All treatment-emergent AEs resolved without any additional treatment and did not lead to discontinuations. No deaths, other SAEs, or significant AEs were reported. There were no clinically relevant changes in laboratory values or vital signs.

Table 1 Demographics and characteristics of healthy male volunteers

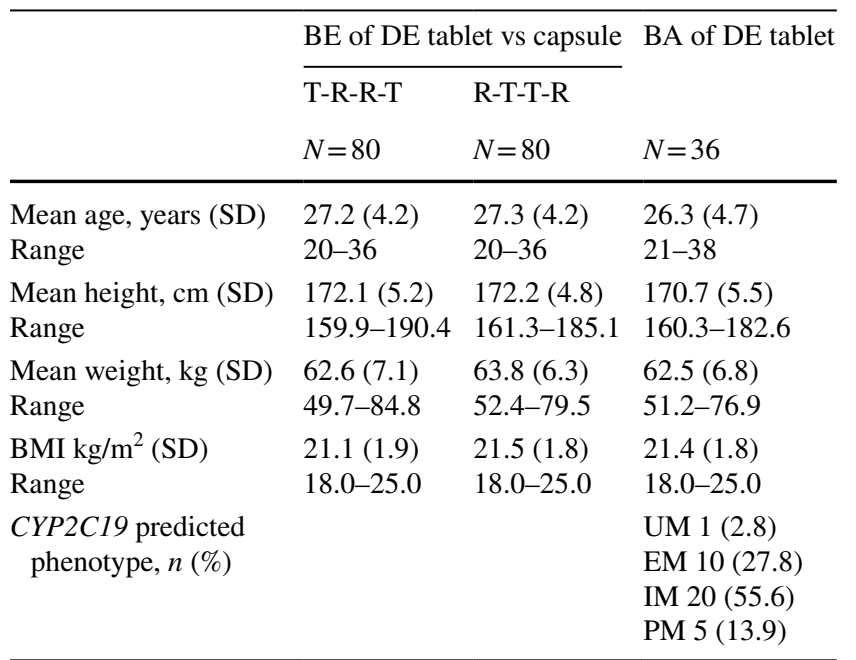

$B A$ bioavailability, $B E$ bioequivalence, $B M I$ body mass index, $D E$ dabigatran etexilate, $E M$ extensive metabolizer, $I M$ intermediate metabolizer, $N$ number of subjects, $P M$ poor metabolizer, $R$ reference treatment, $S D$ standard deviation, $T$ test treatment, $U M$ ultrarapid metabolizer 
Fig. 3 Mean $( \pm S D)$ plasma concentration-time profiles of unconjugated dabigatran after a single 110-mg dose of DE tablet or capsule formulations. $D E$ dabigatran etexilate, $N$ number of subjects, $S D$ standard deviation

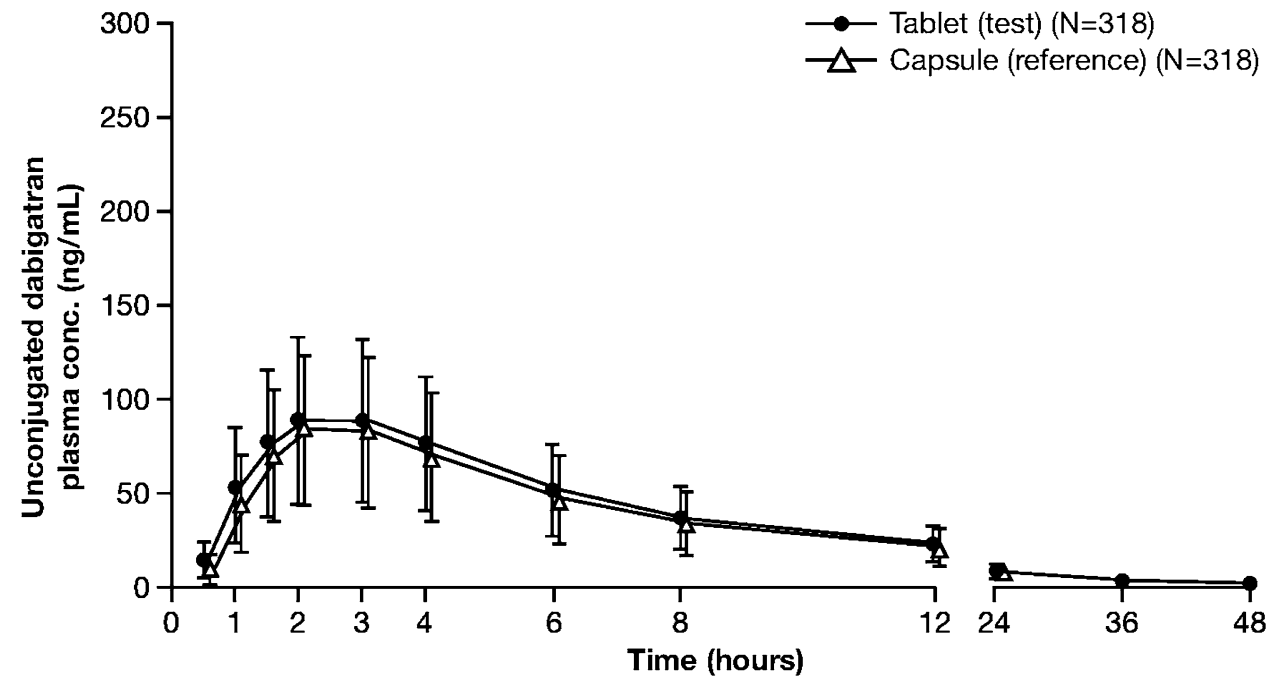

\subsection{Bioavailability of the DE Tablet Alone and Under Pretreatment of Rabeprazole}

\subsubsection{Participant Demographics}

During the study (conducted from 23 May 2017 to 2 August 2017), 36 healthy male volunteers were enrolled, and all participants completed the reference treatment (DE tablet alone; Fig. 2); however, one participant withdrew consent prior to completing test treatment (DE tablet under pretreatment of rabeprazole), and available data obtained prior to withdrawal were included in the analysis. Baseline demographics were as follows: mean age (years \pm SD) $26.3 \pm 4.7$ (range 21-38); mean BMI $\left(\mathrm{kg} / \mathrm{m}^{2} \pm \mathrm{SD}\right.$ ) $21.4 \pm 1.8$ (range 18.0-25.0) (Table 1).

\subsubsection{Pharmacokinetics}

The arithmetic mean plasma concentrations of total dabigatran under rabeprazole pretreatment were lower than those for the reference treatment (DE tablet alone; Fig. 4). Plasma concentration of total dabigatran peaked approximately $2 \mathrm{~h}$ after administration of DE tablet alone and under rabeprazole pretreatment (Fig. 4).

Exposure to total dabigatran $\left(\mathrm{AUC}_{0-\mathrm{tz}}\right.$ and $C_{\max }$ as primary endpoints and $\mathrm{AUC}_{0-\infty}$ as secondary endpoint) were reduced when the DE tablet was administered under rabeprazole pretreatment; gMeans of $\mathrm{AUC}_{0-\mathrm{tz}}$ and $C_{\max }$ decreased from 667 to $192 \mathrm{ng} \mathrm{h} / \mathrm{mL}$ and from 83.1 to $21.8 \mathrm{ng} / \mathrm{mL}$, respectively, while time from dosing to the maximum measured concentration of the analyte in plasma $\left(t_{\max }\right)$ remained unchanged (Table 3).

Overall, BA was decreased by approximately $70 \%$ when the DE tablet was administered under rabeprazole pretreatment: the adjusted gMean ratios of total dabigatran were
28.9\% (90\% CI 21.3-39.0) for $\mathrm{AUC}_{0-\mathrm{tz}}$ and $26.4 \%$ (90\% CI 20.1-34.7) for $C_{\max }$ (Table 4).

Similar pharmacokinetic trends were observed for unconjugated dabigatran (Tables 3 and 4).

\subsubsection{Gastric $\mathrm{pH}$}

The mean gastric $\mathrm{pH}$ ranged from 2.07-2.51 within $2 \mathrm{~h}$ post-treatment with the DE tablet alone. Administration of DE under rabeprazole pretreatment resulted in an increased mean gastric $\mathrm{pH}$ range of 5.27-6.23. Gastric $\mathrm{pH}$ tended to be higher in participants with predicted lower CYP2C19 activity (data not shown).

\subsubsection{Safety}

Overall, treatment with the DE tablet alone and under rabeprazole pretreatment were both well tolerated. One mild AE (vessel puncture site hypoesthesia) was reported during the treatment period for a patient who received the DE tablet under rabeprazole pretreatment; however, this was considered unrelated to the study drugs. No deaths, SAEs, or other significant AEs were reported. There were no clinically relevant changes in laboratory values or vital signs.

\section{Discussion}

DE is currently available in capsule formulations; we developed a simplified small tablet formulation for use in elderly patients or those with difficulty swallowing. The novel tablet formulation of DE successfully demonstrated $\mathrm{BE}$ with the commercially available capsule in healthy young male volunteers. However, in the BA study investigating the effect of PPI-induced elevated gastric $\mathrm{pH}$ on exposure to the tablet, 




rabeprazole pretreatment led to a substantial decrease in BA not observed with the capsule.

Pretreatment with rabeprazole was anticipated to reflect the status of patients with low gastric acidity and/or that observed in the majority of elderly patients, by elevating intragastric $\mathrm{pH}$ [16-18]. Rabeprazole is commercially available and is widely used in Japan. Ability to measure gastric $\mathrm{pH}$ after PPI administration would be a valuable tool, allowing investigators to track acidity during investigations and potentially compare this with any subsequent effects on pharmacokinetic parameters. The 4-h staggered administration of rabeprazole and DE on the day of assessment of DE pharmacokinetics was done to achieve an intragastric $\mathrm{pH}$ around 5.5, considered to reflect the status of hypoacidity [19]. Mean gastric $\mathrm{pH}$ was 5.3 at the time of DE administration, and was kept between $\mathrm{pH}$ 5.3-6.2 within $2 \mathrm{~h}$ posttreatment of BE. Thus, since gastric $\mathrm{pH}$ was around 5.5 or higher during DE absorption, we considered that rabeprazole pretreatment would achieve the appropriate conditions for the purpose of this study, i.e., to investigate the influence of elevated gastric $\mathrm{pH}$ on exposure to the novel DE tablet.

Solubility of DE is pH dependent, and consequently, the effect of $\mathrm{pH}$ on $\mathrm{BA}$ depends on acidifier in the formulation; therefore, it is necessary to investigate the influence of $\mathrm{pH}$ on exposure to any new formulation of DE. Here we showed that pretreatment with the PPI rabeprazole led to an approximately $70 \%$ decrease in BA of the DE tablet, though BE was established in the aforementioned study. When developing genericized products of $\mathrm{DE}$ and demonstrating $\mathrm{BE}$, testing in the presence of food or under pretreatment with PPIs is not consistently demanded by authorities worldwide $[12,14$, 20,21]. For example, the efficacy and safety of two generic formulations of dabigatran currently approved in Canada have not been evaluated in a post-prandial setting or under pretreatment with PPIs [12]. The exact implications of this lack of information for patients are as yet unknown; however, reduced BA of anticoagulant therapy is anticipated, which could in theory result in decreased efficacy, in this case reduced ability to prevent stroke in target populations [12]. Furthermore, guidelines from the European Medicines Agency state that an additional BE study under conditions of multiple-day pretreatment with a PPI, such as pantoprazole (40 mg BID for 4 days), should be conducted in addition to a study under fasting conditions [22]. Such direction is in line with our opinion from the current studies.

The results of this study are in contrast to those observed with the DE capsule in the presence of pantoprazole, where co-administration with pantoprazole decreased the average BA of dabigatran by approximately $20 \%$ [23]. Such data are further supported by a population pharmacokinetic analysis, which suggested that co-administration of the DE capsule with a PPI only mildly reduces dabigatran BA/ exposure (by 12.5\%) in patients with NVAF [24], and that 
Fig. 4 Mean $( \pm S D)$ plasma concentration-time profiles of total dabigatran after a single 110 -mg dose of DE alone or under 20-mg rabeprazole pretreatment. $D E$ dabigatran etexilate, $N$ number of subjects, $S D$ standard deviation

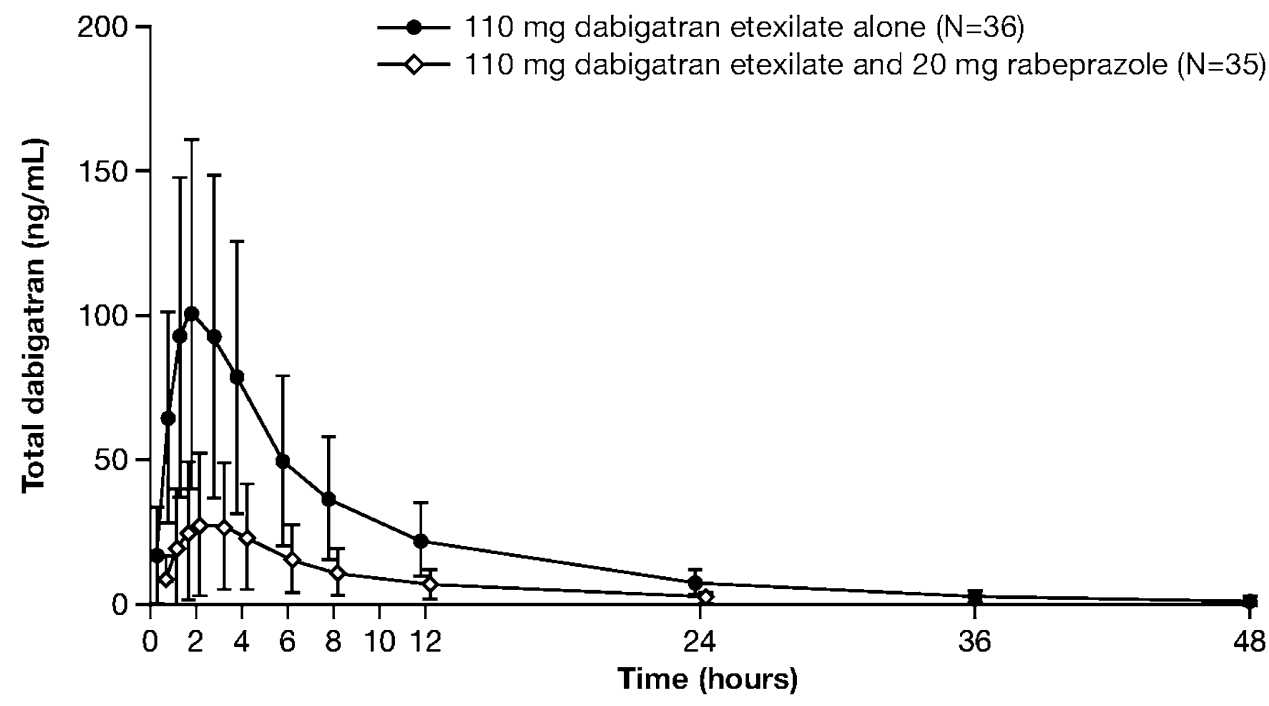

Table 3 Relative BA of the DE tablet alone and under rabeprazole pretreatment: pharmacokinetic parameters of a single 110-mg DE tablet for total and unconjugated dabigatran

\begin{tabular}{|c|c|c|c|c|}
\hline & \multicolumn{2}{|c|}{ DE under pretreatment } & \multicolumn{2}{|l|}{ DE alone } \\
\hline & gMean & $\mathrm{gCV}(\%)$ & gMean & $\mathrm{gCV}$ \\
\hline \multicolumn{5}{|l|}{ Total dabigatran } \\
\hline $\begin{array}{l}\mathrm{AUC}_{0-\mathrm{tz}}(\mathrm{ng} \mathrm{h} / \\
\mathrm{mL})\end{array}$ & $192(n=35)$ & 109 & $667(n=36)$ & 123 \\
\hline $\begin{array}{l}\mathrm{AUC}_{0-\infty}(\mathrm{ng} \mathrm{h} / \\
\mathrm{mL})\end{array}$ & $214(n=35)$ & 96.6 & $702(n=36)$ & 110 \\
\hline$C_{\max }(\mathrm{ng} / \mathrm{mL})$ & $21.8(n=35)$ & 105 & $83.1(n=36)$ & 118 \\
\hline$t_{\max }^{1}(\mathrm{~h})$ & $2.00(n=35)$ & $1.00-4.00$ & $2.00(n=36)$ & $1.00-3.00$ \\
\hline$t_{1 / 2}(\mathrm{~h})$ & $8.18(n=35)$ & 28.2 & $8.59(n=36)$ & 16.0 \\
\hline \multicolumn{5}{|c|}{ Unconjugated dabigatran } \\
\hline $\begin{array}{l}\mathrm{AUC}_{0-\mathrm{tz}}(\mathrm{ng} \mathrm{h} / \\
\mathrm{mL})\end{array}$ & $164(n=35)$ & 110 & $588(n=36)$ & 119 \\
\hline $\begin{array}{l}\mathrm{AUC}_{0-\infty}(\mathrm{ng} \mathrm{h} / \\
\mathrm{mL})\end{array}$ & $188(n=35)$ & 93.4 & $618(n=36)$ & 107 \\
\hline$C_{\max }(\mathrm{ng} / \mathrm{mL})$ & $20.0(n=35)$ & 103 & $72.9(n=36)$ & 114 \\
\hline$t_{\max }^{1}(\mathrm{~h})$ & $2.00(n=35)$ & $1.00-4.00$ & $2.00(n=36)$ & $1.00-4.00$ \\
\hline$t_{1 / 2}(\mathrm{~h})$ & $7.92(n=35)$ & 27.3 & $8.31(n=36)$ & 15.5 \\
\hline
\end{tabular}

$A U C_{0-t z}$ area under the concentration-time curve from baseline to last quantifiable data point, $A U C_{0-\infty}$ area under the concentration-time curve from baseline extrapolated to infinity, $B A$ bioavailability, $C_{\max }$ maximum plasma concentration of dabigatran, $D E$ dabigatran etexilate, $g C V$ geometric coefficient of variation, gMean geometric mean, $n$ number of subjects, $t_{\max }$ time from dosing to the maximum measured concentration of the analyte in plasma, $t_{1 / 2}$ terminal half-life of the analyte in plasma

${ }^{1}$ For $t_{\max }$, the median and range (minimum-maximum) values are provided these effects do not have any clinically relevant impact on efficacy. These results are reflected in the current labeling, which concludes that co-administration of dabigatran with pantoprazole does not require dose adjustments. Of note, the observed differences between the tablet and capsule formulations may be attributed to the astute design of the DE capsule, particularly the acidic core of each pellet, which maintains a low-pH microenvironment necessary for optimal absorption after administration [12].

In terms of study limitations, the current studies enrolled young healthy volunteers, in whom the profile of the DE tablet may differ from that in the target population (elderly patients). The strictly controlled conditions of these studies (e.g., fasting etc.) may also differ from a real-world setting.

In summary, a single-dose DE tablet was bioequivalent to the DE capsule in healthy young volunteers. Exposure of total dabigatran greatly decreased under conditions of elevated gastric $\mathrm{pH}$, meaning that the efficacy of the $\mathrm{DE}$ tablet could be questioned; as such, the DE tablet we tested in this study will not be submitted for a new drug application to the Japanese drug agency. However, our findings highlight the importance of examining BE under normal conditions and relative $\mathrm{BA}$ at elevated gastric $\mathrm{pH}$ when developing novel formulations of drugs with $\mathrm{pH}$-dependent solubility. 
Table 4 Relative BA of the DE tablet alone and under rabeprazole pretreatment: inferential analysis of pharmacokinetic parameters of a single $110-\mathrm{mg}$ DE tablet for total and unconjugated dabigatran

\begin{tabular}{|c|c|c|c|c|}
\hline & \multicolumn{2}{|l|}{ Adjusted gMean } & \multirow{2}{*}{$\begin{array}{l}\text { Adjusted gMean ratio (\%, DE under } \\
\text { pretreatment/DE alone) }\end{array}$} & \multirow{2}{*}{$\begin{array}{l}\text { Two-sided } \\
90 \% \text { CI }(\%)\end{array}$} \\
\hline & DE under pretreatment & DE alone & & \\
\hline \multicolumn{5}{|l|}{ Total dabigatran } \\
\hline $\mathrm{AUC}_{0-\mathrm{tz}}(\mathrm{ng} \mathrm{h} / \mathrm{mL})$ & $192(n=35)$ & $667(n=36)$ & 28.9 & $21.3-39.0$ \\
\hline $\mathrm{AUC}_{0-\infty}(\mathrm{ng} \mathrm{h} / \mathrm{mL})$ & $215(n=35)$ & $702(n=36)$ & 30.6 & $23.3-40.2$ \\
\hline$C_{\max }(\mathrm{ng} / \mathrm{mL})$ & $21.9(n=35)$ & $83.1(n=36)$ & 26.4 & $20.1-34.7$ \\
\hline \multicolumn{5}{|c|}{ Unconjugated dabigatran } \\
\hline $\mathrm{AUC}_{0-\mathrm{tz}}(\mathrm{ng} \mathrm{h} / \mathrm{mL})$ & $165(n=35)$ & $588(n=36)$ & 28.0 & $20.9-37.5$ \\
\hline $\mathrm{AUC}_{0-\infty}(\mathrm{ng} \mathrm{h} / \mathrm{mL})$ & $189(n=35)$ & $618(n=36)$ & 30.6 & $23.4-40.0$ \\
\hline$C_{\max }(\mathrm{ng} / \mathrm{mL})$ & $20.1(n=35)$ & $72.9(n=36)$ & 27.6 & $21.0-36.1$ \\
\hline
\end{tabular}

$A U C_{0-t z}$ area under the concentration-time curve from baseline to last quantifiable data point, $A U C_{0-\infty}$ area under the concentration-time curve from baseline extrapolated to infinity, $B A$ bioavailability, $C I$ confidence interval, $C_{\max }$ maximum plasma concentration of dabigatran, $D E$ dabigatran etexilate, gMean geometric mean, $n$ number of subjects

\begin{abstract}
Acknowledgements We thank all the subjects involved in these studies. Medical writing assistance, funded by Nippon Boehringer Ingelheim, was provided by Mai Kurihara, Ashfield Healthcare Communications, part of UDG Healthcare plc. Publication management and editorial support were provided by Kimiko Mitani of Nippon Boehringer Ingelheim. The bioanalysis was supported by Dietmar Gansser of Boehringer Ingelheim Pharma GmbH \& Co. KG. The authors also thank Dr. Sebastian Haertter, Dr. Fenglei Huang, Dr. Shinji Tatami, Dr. Jutta Heinrich-Nols, Dr. Joanne VanRyn and Mr. Yasuhisa Urano for their valuable advice from the study planning to interpretation of results and peer review.
\end{abstract}

\section{Compliance with Ethical Standards}

Funding These studies were financially supported by Nippon Boehringer Ingelheim.

Conflict of Interest Akiko Harada: employee of Nippon Boehringer Ingelheim Co., Ltd. Ippei Ikushima: no conflicts of interest to disclose. Miwa Haranaka: no conflicts of interest to disclose. Aki Yanagihara: employee of Nippon Boehringer Ingelheim Co., Ltd. Daisuke Nakayama: employee of Nippon Boehringer Ingelheim Co., Ltd.

Informed Consent All participants provided written informed consent.

Data Sharing Policy To ensure independent interpretation of clinical study results, Boehringer Ingelheim grants all external authors access to all relevant material, including participant-level clinical study data, as needed by them to fulfill their role and obligations as authors under the International Committee of Medical Journal Editors (ICMJE) criteria. Furthermore, clinical study documents (e.g., study report, study protocol, statistical analysis plan) and participant clinical study data are available to be shared after publication of the primary manuscript in a peer-reviewed journal and if regulatory activities are complete and other criteria met per the Boehringer Ingelheim Policy on Transparency and Publication of Clinical Study Data: https://trials.boehringer -ingelheim.com/transparency_policy.html. Prior to providing access, documents will be examined and, if necessary, redacted and the data will be de-identified, to protect the personal data of study participants and personnel and to respect the boundaries of the informed consent of the study participants. Clinical Study Reports and Related Clinical Documents can be requested via this link: https://trials.boehringer-ingel heim.com/trial_results/clinical_submission_documents.html. All such requests will be governed by a Document Sharing Agreement. Bona fide, qualified scientific and medical researchers may request access to de-identified, analyzable participant clinical study data with corresponding documentation describing the structure and content of the datasets. Upon approval, and governed by a Data Sharing Agreement, data are shared in a secured data-access system for a limited period of 1 year, which may be extended upon request. Researchers should use https://vivli.org/ to request access to study data.

Open Access This article is distributed under the terms of the Creative Commons Attribution-NonCommercial 4.0 International License (http://creativecommons.org/licenses/by-nc/4.0/), which permits any noncommercial use, distribution, and reproduction in any medium, provided you give appropriate credit to the original author(s) and the source, provide a link to the Creative Commons license, and indicate if changes were made.

\section{References}

1. Connolly SJ, Ezekowitz MD, Yusuf S, Eikelboom J, Oldgren J, Parekh A, et al. Dabigatran versus warfarin in patients with atrial fibrillation. N Engl J Med. 2009;361:1139-51. https://doi. org/10.1056/NEJMoa0905561.

2. Hori M, Connolly SJ, Zhu J, Liu LS, Lau CP, Pais P, et al. Dabigatran versus warfarin: effects on ischemic and hemorrhagic strokes and bleeding in Asians and non-Asians with atrial fibrillation. Stroke. 2013;44:1891-6. https://doi.org/10.1161/STROK EAHA.113.000990.

3. Hori M, Connolly SJ, Ezekowitz MD, Reilly PA, Yusuf S, Wallentin $\mathrm{L}$, et al. Efficacy and safety of dabigatran vs. warfarin in patients with atrial fibrillation-sub-analysis in Japanese population in RE-LY trial. Circ J. 2011;75:800-5. https://doi. org/10.1253/circj.CJ-11-0191.

4. Inoue H, Uchiyama S, Atarashi H, Okumura K, Koretsune Y, Yasaka M, et al. Effectiveness and safety of long-term dabigatran among patients with non-valvular atrial fibrillation in clinical practice: J-dabigatran surveillance. J Cardiol. 2019;74:156-63. https://doi.org/10.1016/j.jjcc.2018.12.013. 
5. JCS Joint Working Group. Guidelines for pharmacotherapy of atrial fibrillation (JCS 2013). Circ J. 2014;78:1997-2021. https:// doi.org/10.1253/circj.CJ-66-0092.

6. Wann LS, Curtis AB, Ellenbogen KA, Estes NA 3rd, Ezekowitz MD, Jackman WM, et al. 2011 ACCF/AHA/HRS focused update on the management of patients with atrial fibrillation (update on dabigatran): a report of the American College of Cardiology Foundation/American Heart Association Task Force on practice guidelines. Circulation. 2011;123:1144-50. https://doi. org/10.1161/CIR.0b013e31820f14c0.

7. Evaluation and Licensing Division, Pharmaceutical and Food Safety Bureau. Ministry of Health, Labour and Welfare. Report on the deliberation results for Pradaxa 75 and $100 \mathrm{mg}$ capsules. http://www.pmda.go.jp/files/000207341.pdf. Accessed 17 Oct 2019.

8. Morris H. Administering drugs to patients with swallowing difficulties. Nurs Times. 2005;101:28-30.

9. Notenboom K, Beers E, van Riet-Nales DA, Egberts TC, Leufkens HG, Jansen PA, et al. Practical problems with medication use that older people experience: a qualitative study. J Am Geriatr Soc. 2014;62:2339-44. https://doi.org/10.1111/jgs.13126.

10. Inoue H, Fujiki A, Origasa H, Ogawa S, Okumura K, Kubota I, et al. Prevalence of atrial fibrillation in the general population of Japan: an analysis based on periodic health examination. Int J Cardiol. 2009;137:102-7. https://doi.org/10.1016/j.ijcar d.2008.06.029.

11. European Medicines Agency. Pradaxa ${ }^{\circledR}$ Assessment Report. http://www.ema.europa.eu/docs/en_GB/document_library/ EPAR_-_Public_assessment_report/human/000829/WC50004106 2.pdf. Accessed 17 Oct 2019.

12. Weitz JI, Earl KM, Leblanc K, Semchuk W, Jamali F. Establishing therapeutic equivalence of complex pharmaceuticals: the case of dabigatran. Can J Cardiol. 2018;34:1116-9. https://doi. org/10.1016/j.cjca.2018.05.023.

13. Eikelboom JW, Wallentin L, Connolly SJ, Ezekowitz M, Healey JS, Oldgren J, et al. Risk of bleeding with 2 doses of dabigatran compared with warfarin in older and younger patients with atrial fibrillation: an analysis of the randomized evaluation of long-term anticoagulant therapy (RE-LY) trial. Circulation. 2011;123:236372. https://doi.org/10.1161/CIRCULATIONAHA.110.004747.

14. National Institute of Health Sciences. Guideline for bioequivalence studies of generic products. Available at: http://www.nihs. go.jp/drug/be-guide(e)/Generic/GL-E_120229_BE.pdf. Accessed 17 Oct 2019.

15. Blech S, Ebner T, Ludwig-Schwellinger E, Stangier J, Roth W. The metabolism and disposition of the oral direct thrombin inhibitor, dabigatran, in humans. Drug Metab Dispos. 2008;36:386-99. https://doi.org/10.1124/dmd.107.019083.
16. Musib L, Choo E, Deng Y, Eppler S, Rooney I, Chan IT, et al. Absolute bioavailability and effect of formulation change, food, or elevated $\mathrm{pH}$ with rabeprazole on cobimetinib absorption in healthy subjects. Mol Pharm. 2013;10:4046-54. https://doi.org/10.1021/ mp400383x.

17. Malhi V, Colburn D, Williams SJ, Hop CE, Dresser MJ, Chandra $\mathrm{P}$, et al. A clinical drug-drug interaction study to evaluate the effect of a proton-pump inhibitor, a combined P-glycoprotein/ cytochrome 450 enzyme (CYP)3A4 inhibitor, and a CYP2C9 inhibitor on the pharmacokinetics of vismodegib. Cancer Chemother Pharmacol. 2016;78:41-9. https://doi.org/10.1007/s0028 0-016-3020-z.

18. Ware JA, Dalziel G, Jin JY, Pellett JD, Smelick GS, West DA, et al. Impact of food and the proton pump inhibitor rabeprazole on the pharmacokinetics of GDC-0941 in healthy volunteers: bench to bedside investigation of $\mathrm{pH}$-dependent solubility. Mol Pharm. 2013;10:4074-81. https://doi.org/10.1021/mp4005595.

19. National Institute of Health Sciences. Guideline for bioequivalence studies of generic products Q \& A. http://www.nihs.go.jp/ drug/be-guide(e)/Generic/QA-E_120229_BE.pdf. Accessed 17 Oct 2019.

20. European Medicines Agency. Guideline on the investigation of bioequivalence. https://www.ema.europa.eu/en/documents/scien tific-guideline/guideline-investigation-bioequivalence-rev1_ en.pdf. Accessed 17 Oct 2019.

21. U.S. Food and Drug Administration. Bioavailability and Bioequivalence Studies Submitted in NDAs or INDs - General Considerations. 2014. https://www.fda.gov/regulatory-information/searc h-fda-guidance-documents/bioavailability-and-bioequivalencestudies-submitted-ndas-or-inds-general-considerations. Accessed 17 Oct 2019.

22. European Medicines Agency. Dabigatran etexilate hard capsule $75 \mathrm{mg}, 110 \mathrm{mg}$ and $150 \mathrm{mg}$ product-specific bioequivalence guidance. https://www.ema.europa.eu/en/documents/scientific-guide line/dabigatran-etexilate-hard-capsule-75-mg-110-mg-150-mgproduct-specific-bioequivalence-guidance_en.pdf. Accessed 17 Oct 2019.

23. Stangier J, Stahle H, Rathgen K, Fuhr R. Pharmacokinetics and pharmacodynamics of the direct oral thrombin inhibitor dabigatran in healthy elderly subjects. Clin Pharmacokinet. 2008;47:47-59. https://doi.org/10.2165/00003088-20084701000005 .

24. Liesenfeld KH, Lehr T, Dansirikul C, Reilly PA, Connolly SJ, Ezekowitz MD, et al. Population pharmacokinetic analysis of the oral thrombin inhibitor dabigatran etexilate in patients with nonvalvular atrial fibrillation from the RE-LY trial. J Thromb Haemost. 2011;9:2168-75. https://doi.org/10.1111/j.1538-7836.2011.04498.x.

\section{Affiliations}

\section{Akiko Harada $^{1}$ (D) Ippei Ikushima ${ }^{2} \cdot$ Miwa Haranaka $^{3} \cdot$ Aki Yanagihara $^{4} \cdot$ Daisuke Nakayama $^{4}$}

1 Clinical PK/PD Department, Nippon Boehringer Ingelheim Co., Ltd., 6-7-5 Minatojima Minamimachi, Chuo-ku, Kobe, Hyogo 650-0047, Japan

2 SOUSEIKAI Sumida Hospital, 1-29-1 Honjo, Sumida-ku, Tokyo 130-0004, Japan
3 SOUSEIKAI Hakata Clinic, 6-18 Tenyamachi, Hakata-ku, Fukuoka 812-0025, Japan

4 Medicine Division, Nippon Boehringer Ingelheim Co., Ltd., 2-1-1 Osaki, Shinagawa-ku, Tokyo 141-6017, Japan 